\title{
Emotional Regulation Strategies (ER) Used by Trainees to Overcome Negative Emotions
}

\author{
Fauzia Butt ( $\nabla$ drfauziabutt@hotmail.com ) \\ Sharif Medical And Dental College/ Sharif Medical City Hospital , Lahore, Pakistan \\ Usman Mahboob \\ Institute of Health Professions Education and Research, Khyber Medical University, Pakistan \\ Gohar Wajid \\ Consultant Health Professions Education \\ Rehan Ahmad Khan \\ IMC-T, Department of Surgery Riphah International University, Islamabad
}

\section{Research Article}

Keywords: Negative Emotions, emotion regulation strategies, emotional labour, trainees, postgraduation

Posted Date: May 20th, 2021

DOI: https://doi.org/10.21203/rs.3.rs-508989/v1

License: @ (i) This work is licensed under a Creative Commons Attribution 4.0 International License. Read Full License 


\section{Abstract}

Background: Trainee doctors undergo a complex process of emotional labour at the workplace. The presence of any negative emotion affects not only their professional and caring competency but also their mental health. The purpose of this study is to identify the use of different emotion regulation (ER) strategies in Sad, Disgust, Fear, Anger, and Shock situations, and to determine the frequency and the predominant pattern of emotional response in the emotion triggering situations.

Methods: This cross-sectional study was done in two public and one private-sector medical college in Lahore, Pakistan, in 2019. Gross Theory of emotion and situational model of emotion regulation was used to develop a questionnaire and to interpret the findings. Based on Gross Theory, emotion regulation strategies were situation selection (SS), situation modification (SM), cognitive change (CC), attention deployment (AD), and response modulation (RM). The results were analysed using chi-square and repeated-measures ANOVA on SPSS 25.

Results: Out of the 377 trainees, 308 participated in this study. Most of them were from the Obstetrics \& Gynaecology (43.2\%) department and in the Year-1 of training (37.7\%). The most frequent emotion triggering situation was prolonged working hours (95\%). The major emotional response was quietness $(50 \%)$ and this reaction was observed in situations of the rude behaviour of patients and their attendants toward staff $(60 \%)$.

The trainees used greater ER strategies in sad situations (Mean $3.49 \pm 1.79 ; F=1823, p<0.01$ ). Trainees managed sad emotions by keeping themselves involved in other activities (49\%) and with an outward response (50\%). In anger; they blamed others (40.3\%) and ruminated (32.8\%). In fear; suppression of emotions (28.6\%) and focus on the task (23.1\%) were the most common ER strategies. When disgusted, avoidance (29.2\%); and suppression of emotions (28.9\%) were used. In shock, acceptance (12.7\%) and suppression of emotion (8.4\%) were preferred ER strategies.

Conclusion: Trainees struggle to manage emotions and use maladaptive strategies that are avoiding situations, focusing on other activities, blaming others, rumination, thought suppression, and outward behaviours. Developing emotional skill programs to manage negative emotions can improve mental health, job satisfaction, and patient care.

\section{Background}

Emotions are of fundamental importance in the life of every health professional and these emotions affect their social behaviour [1]. Health professionals interact with patients and colleagues and in this phase of learning undergoes a complex process of emotional labour [2]. This process of emotional labour is greatest among junior doctors and in trainees dealing with emotionally challenging situations (3)]. High workloads and responsibilities place these doctors at higher risk of developing mental health problems and burn out [4].

Emotional regulation is a multifaceted process that is having a valance response (positive or negative), behavioural and physiological response that is accompanied by specific thoughts and feelings [5].

The positive emotions help in decision making, define an appropriate course of action, inform about other behavioural intentions and motivate socially appropriate behaviour and change the situation that displays the emotion in desirable ways [6].

Harmful emotions are negative emotions that are sadness, shock, fear, disgust, and anger aroused in difficult situations which need to be managed by the emotional regulation process [7].

Harmful emotions are associated with mal-adaption in cognition and behaviour [8]. Research has shown that emotionally intelligent people are more capable of managing emotions [9]. Emotionally intelligent doctors not only perceive, facilitate, understand, and manage their emotions but also handle their patients well $[10,11]$.

The Gross Process Model describes that individuals can control emotions through the emotional regulation process by using some strategies and these emotions unfold over some time [12]. Strategies are categorized into both antecedents-focused and response-focused [Fig. 1]. Antecedentfocused strategies occur during the genesis of emotion and response-modulation strategies occur after the experience of emotion [13]. Antecedentfocused strategies are situation selection (SS), situation modification (SM), attention deployment (AD), and cognitive change (CC) that occur in sequence $[14,11]$.

Most studies reported in literature focused on one or more strategies that are, re-appraisal and expressive suppression to manage emotions [14,3]. However, in negative emotional situations, the person can use multiple strategies for the same situation rather than a single strategy to control emotions [15]. Some strategies are used on encountering the situation, other during and a few after the situation. The situational model based on the Gross Theory of emotion is used to answer a research question; as to how a trainee uses multiple strategies in five negative emotions that change over sometime [Fig. 2]. This theoretical model helps in determining the relative success of strategies employed in clinical settings [7].

In literature, qualitative studies are done on a cluster of negative emotions and were outside the clinical health care settings $[15,16,17]$. There is a gap in the literature on the emotional regulation process used in five discrete negative emotions. Considering the lack of literature on emotion regulation and its management in a clinical setting, we aimed to identify the use of different emotion regulation (ER) strategies in dealing with negative emotions such as sad, disgust, fear, anger, and shock, and to determine the frequency and the predominant pattern of emotional response in the emotion triggering situations. Postgraduate training is one of the most stressful times as these trainees surrogate for consultants and is more liable to make 
mistakes due to inexperience. Therefore, we planned to explore the emotional regulation and management of trainees to have a complete picture of their emotional health that may help us in understanding the mental health and emotional competency of trainees. As control of negative emotions and generation of positive emotion is a need of the hour for the emotional development process among our trainees who are facing professional dilemmas in becoming and being a doctor [18].

\section{Methodology}

Study Design \& Setting

This descriptive cross-sectional study was conducted in three teaching hospitals in Lahore, Pakistan in 2019. Among them, Sharif Medical City Hospital is a tertiary care 350 beds, a private teaching hospital that served 53496 patients in the outpatient department (OPD) and 5794 were in-patient admissions (IPA), and 3963 major and minor surgeries were performed in the year 2019.

Lady Willingdon Hospital is a public sector 235 beds, the largest maternity hospital in Pakistan affiliated with King Edward medical university served around 95952 patients in OPD and 33327 in indoor. And more than 9498 major and minor surgeries and 16375 deliveries were performed in the year 2019.

Aziz Bahati Hospital affiliated with Nawaz Sharif Medical College Gujrat is a 550-bed, public sector hospital in which more than 55000 patients visited OPD and 21000 in an emergency, and 4500 major \& minor surgeries were performed per month in the year 2019.

\section{Ethical approval}

The study protocol was carried out in accordance with the Deceleration of Helsinki guidelines and regulations. Institutional Review Board (IRB) at the University of Lahore and the participating institutions approved the study.

\section{Consent to Participate}

A written informed consent was taken from all participants. A cover letter was generated at the beginning of the questionnaire to inform the trainees about the purpose of the research and consent for participation. They were assured of the confidentiality of the data and the option of refusal if they don't want to participate in research. The anonymity of the data was ensured.

\section{Participants}

The post-graduate training in Pakistan is offered by the College of Physicians and Surgeons Pakistan (CPSP) and is most similar in structure followed in the UK by the Royal Colleges. The training varies from 4-5 years depending on the speciality. The general speciality training is four years such as General Surgery, Obstetrics and Gynaecology, and General Medicine whereas the sub-speciality training consists of five years duration. This study targeted postgraduate medical trainees from all clinical disciplines, from Year- 1 to Year- 4 while medical students and house officers were excluded from the study.

\section{Sample selection}

A sample size of 377 postgraduate medical trainees was calculated through online software, open epi using a confidence interval of $95 \%$ and margin of error of $5 \%$. The convenient sampling technique was used to get the sample population [7].

\section{Questionnaire development}

The data was collected by questionnaires designed for this research. As there was no relevant questionnaire that could comply with the objectives of our study so we developed a questionnaire following the steps given in the AMEE guide 87 [19].

Step 1 was a literature search so themes were identified from the literature search to define the construct and the measures related to the emotional regulation construct. To measure construct ten items were developed for the $1^{\text {st }}$ questionnaire and twenty-one items for the $2^{\text {nd }}$ questionnaire [ 20,21 , $22,23,24,7]$.

The first questionnaire (Emotional situations and response questionnaire) has 2 components, the $1^{\text {st }}$ component was on emotion eliciting situations and $2^{\text {nd }}$ component were emotional responses to these situations.

The second questionnaire(Emotion regulation strategies questionnaire) was on emotion regulation strategies in negative emotions.

Step 2 involved discussions among coauthors to develop a valid questionnaire and to ensure that the conceptualization of the construct makes theoretical sense and its language for the population of interest.

Step 3 was the synthesis of data, and step 4 was updating the items. 
Step 5 involved content validations, for which the questionnaires were emailed to 12 experts including subject specialists; psychologist and medical educationalists. The content validity forms were sent to these experts via email and were instructed to score for relevance, comments, and suggestions (acceptance, rejection with reason, and modification) for each item. The relevance of items was based on the score of each item from 1-4 (1: not relevant, 2: somewhat relevant, 3: quite relevant, and 4: very relevant). Items were further refined on their feedback.

Content validity index of individual items (I-CVI) and of the scale (S-CVI) was calculated with two methods, S-CVI/Average and S-CVI/UA (universal agreement) using the rating of items based on relevance by content experts [Annexure 1].

Step 6 involved cognitive probing for trainees' understanding. Five trainees from the Obstetrics \& Gynaecology department were selected for concurrent verbal cognitive probing. Criteria used for concurrent probing include correct item interpretation, comprehensible explanation, answer choice compatibility with interpretation, and overall item cognition across the five trainees.

Step 7 involved pilot testing and final modification to adjust items hence two questionnaires were distributed randomly to sixty-five postgraduate trainees selected from different clinical specialities to determine the reliability of the instrument. The reliability was calculated using Conrbach alpha and split-half reliability. The first questionnaire had two components whereas the second questionnaire only had one component. Cronbach alpha was calculated for the $1^{\text {st }}$ component of the questionnaire and a split-half reliability test was used for the $2^{\text {nd }}$ component of the first questionnaire. For the second questionnaire, only split-half reliability was calculated for multiple response analysis.

First Questionnaire (Emotional situations and response questionnaire)

The first component of this questionnaire comprised of ten situations with a range of options on a Likert scale ranging from 0 to 5 (Never, Rarely, Sometimes, Often, Always) for each item. These items inquired about the situations at the workplace which generate negative emotions. In the second component of this questionnaire, the emotional response of trainees in these situations was inquired.

Second Questionnaire:(Emotion regulation strategies questionnaire)

This questionnaire comprised of 18-items about strategies to regulate negative emotions based on the Gross Theory of emotions [Fig 1]. These items were categorized into prior, during, and after the negative emotional situation using the situational model [Fig 2], and responses were five different emotions described in the literature (Fear, Disgust, Sad, Angry, and Shock) against which these strategies were used. Strategies were operationally defined as:

1. Situation Selection (SS): To attend or not to attend the situation.

2. Situation Modification (SM): Modifying the situation after attending.

3. Attention Deployment (AD): Redirecting attention towards or away from the situation.

4. Cognitive Change (CC): Using some coping strategies to manage the situation like acceptance, planning, reappraisal, positive refocusing, putting into perspective.

5. Response Modulation (RM): Response after the situation like watching TV, walk exercise, discussion with others, and suppression of emotions.

\section{Data Analysis Procedure}

The objective was to describe the score obtained on the frequency of negative situations and the percentages calculated for different emotional reactions and strategies used during each emotional reaction. The Statistical Package for Social Science-SPSS 25 was used for data entry and analysis. The demographic data were presented using descriptive statistics for categorical variables, age, gender, year of study, department speciality in the form of frequencies and percentages. P-value calculated for comparison of strategies among gender group and year of training.

To determine the frequency of emotion triggering situations as part of dilemmas in professional life, responses of $1^{\text {st }}$ part of the questionnaire (how frequently you encounter these situations that is (Always, Often and Sometimes) were merged into "Yes" and those as (Never and Rarely) into "No".

Repeated measures (ANOVA) were used to determine the significant negative emotional situation using strategies in different phases (Phase 1; prior, Phase Il; during and, Phase III; after the situation). Moreover, repeated-measures ANOVA was used to investigate the mean difference of specific variables (Negative emotional situation as in our study) within-subjects for correlated samples. Repeated measures ANOVA is an extension of paired ttest (pre and post), where subjects were assessed at multiple time points or data is collected from all respondents (subjects) at multiple levels. In our study, the information (responses of negative emotional state for different strategies) was collected from subjects before, during, and after the situation.

F-Ratio is a statistical measure to express the results of repeated measures ANOVA and p-value describes the significance of results. A high $F$ value indicates rejection of the null hypothesis that group means are equal, and also that variability of group means is larger relative to within-group variability, and this value at $95 \%$ Confidence interval must be larger than 64.19

\section{Results}

Page $4 / 14$ 


\section{Pilot testing and Questionnaire development}

During the questionnaire development, ten items were developed for the first questionnaire on emotion triggering situations and emotional response to situations and 18 items for emotion regulation strategies in five negative emotions for the second questionnaire. All items were rated as relevant and fully understandable with an inter-item reliability index (Annexure 1).

The content validity index obtained for the first questionnaire was S-CVI/Ave 0.9 and S-CVI/UA 0.7 . Internal consistency measured by Cronbach alpha was 0.77 .

The second questionnaire had S-CVI/Ave of 0.9 and S-CVI/UA of 0.80 respectively and internal consistency using the "split-half Procedure" was 0.8 .

\section{Demographics of the participants}

A total of $308 / 377$ (response rate $=81.7 \%$ ) trainees participated in the study. The mean age of the participants was $27.8 \pm 2.91$, and among them $67 \%$ were females and $33 \%$ were males. The majority of the trainees were from the Obstetrics \& Gynaecology department (43.2\%) and in the Year-one (37.7\%) of training (Table 1$)$.

When trainees were inquired about the frequency of emotion triggering situations, (95\%) recognized prolonged working hours as the most emotion triggering event followed by the rude behaviour of patients or their attendant towards staff (91\%). The emotional reaction in ten different situations varies. In five out of ten situations, the major emotional response was quietness followed by a discussion with others (three out of ten) and aggressiveness (two out of ten) (Table 2).

Regarding the pattern of emotional regulation strategies, on encountering a situation, trainees managed sad emotions with greater use of SM (49\%) and in disgusting situations, SS (29.2\%) was used as a preferable strategy. In angry and shock state reappraisal (30.8\% \& 6.8\%) while in state of fear, expressive suppression (28.6\%) was used as preferable strategies on encountering the situation.

During the situation, in sad emotions; rumination (41.6\%), in anger; they blame others (40.3\%) when disgusted; focus on planning (24\%), in fear; distraction (23.1\%), and in shock; acceptance (12.7\%). When trainees are angry, maladaptive strategies are used including blaming others (40.3\%) and rumination $(32.8 \%)$.

After the situation, in sad emotions outward response was crying (50.6\%); in anger, the physical distraction that is watching TV, shopping (33.1\%); in fear; take a pill (21.1\%), and in disgust (28.9\%) and shock (8.4\%); suppression of emotions were preferable strategies (Table 3 ).

All these strategies were mostly used by Year- 1 trainees followed by Year- 2 trainees. When strategies were compared in the sad emotional situations among the gender group; more females used these strategies. Before the situation, $47.5 \%$ of females used these strategies in comparison with $25.4 \%$ males, while during situations; $54.2 \%$ females versus $26.3 \%$ males, and after the situation; $57.5 \%$ females versus $27.9 \%$ males used these strategies for control of negative emotions (Table 4). The trainees use greater ER strategies during sad situations in comparison to other negative emotions (Mean sad $3.49 \pm 1.79 ; F=1823, p<0.01)$; (Mean anger $2.86 \pm 1.92, F=1056.394, p<0.01)$; (Mean fear $2.86 \pm 1.92 ; F=993.434, p<0.01) ;($ Mean disgust $1.94 \pm 1.66$; $\mathrm{F}=544.932, \mathrm{p}<0.01)$; and (Mean shock $0.76 \pm 1.09 ; \mathrm{F}, 136.122, \mathrm{p}<0.01)$ situations (Table 5).

\section{Discussion}

Dealing with emotions and learning to manage emotions is an important component of professional behaviour. Workplace and clinical environments are far from ideal places and trainee doctors should transform seamlessly from students to professional individuals to face stressful situations, as patiently as possible.

The emotionally challenging situations could be due to personal factors (personality trait, career development, and opportunities, mental health problems), interpersonal relationship factors (colleagues, staff nurses, and patients and their relatives), organizational and responsibility factors (prolonged working hours). The major factor identified to be responsible for emotion generating events in this study was prolonged working hours (95\%), followed by the rude behaviour of patients or their attendant towards health professionals (91\%).

Previous studies found that the number of work hours per week was associated with a higher risk of burnout and greater risks of mental health issues [4]. The results of our study differed from other studies in which emotionally challenging situations identified were medical errors, the conflict between educational interest and patient needs, disgust with patient safety, consent, identity, and abuse [25,21].

Incidences of the rude behaviour of patients and their relatives are becoming increasingly common and are a source of anger, disrespect and affect the interaction between patients and doctors and identified as a second major emotionally challenging factor in this study. Therefore, understanding the perspective of patients and effective communication strategy, in simulation-based learning appears to be an effective tool in the teaching of trainees to handle conflicts of patients generated at the workplace and this has been reflected in a study conducted by Keskitalo on "students emotions in simulation-based medical education" in 2017 [26]. The simulation-based training to a manage conflict situation is not yet routinely practised in the hospitals that took part in this study 
The emotional response of individuals varies in different situations and reflects the emotional sensitivity to that situation. Koole in 2010 in an integrative review on the psychology of emotion regulation described that emotional sensitivity (initial response) to the situation is not only influenced by the nature of stimuli but also by personal characteristic (personality trait) which will determine the subsequent coping response of an individual that is emotion regulation process [5,27]. In our study, we also determined the emotional responses generated in different situations. We identify a total of ten situations that can trigger negative emotions. In five out of ten situations, the major emotional response (60\%) was quietness followed by a discussion with others and aggressiveness, when there was rude behaviour of patients. The results are comparable to earlier studies conducted by Doulougeri $\mathrm{K}$ in 2016 on medical students, in which the most important reaction was inaction [28]. The reason might be that most of the trainees were from the Year-1, lower down in the hierarchy, they felt powerless, had limited knowledge and experience, and failed to struggle with challenging situations that influenced their emotional and behavioural response.

In addition to identifying the frequency of negative emotions, another important element is how trainees react to negative emotions. We found that in our study, $95 \%$ of respondents recognized prolonged working hours as a major factor in negative emotion generation, the most common emotional reaction was aggressiveness (36\%) followed by loss of interest in work (24\%) and both are emotion-focused maladaptive responses. The results are consistent with findings on junior doctors in Australia that work-related stress is identified as a major reason for psychological distress. Hence identification of emotional sensitivity of the individuals and then management of psychologically distressed interns are required at the organizational level [29], [27].

In our study, most of the trainees used the strategies in a sad emotional situation (Mean $3.49 \pm 1.79 ; F=1823, p<0.01$ ) followed by anger, fear, disgust, and shock. The results of our study are also comparable to Dixon and Zimmerman in which more strategies are used in sad emotions compared to anger $[30,17]$. These findings depict that trainees use regulation strategies differently depending upon the emotion being regulated.

In our study, we also determined the emotional regulation strategies in five negative emotions from the perspective of the Gross theory of emotion regulation. When mapped over some time, the results of our study depict that on encountering the situation, SM (49\%) strategy was used when dealing with sad emotions, while in disgusting situation SS strategy (29.2\%) was preferred. The study conducted by Monrouxe on foundation doctors in the UK also found that before the situation most of the F1 used situation modification strategies [3]. The findings are also consistent with the study by Webb et al that when people have difficulty in the use of cognitive coping strategies and are poor at regulating emotions in high-intensity situations; SS strategy is used to prevent the emotional development process [31].

Reappraisal is more effective in down-regulating negative emotional experience; in our study trainees manage anger (30.8\%) by using this strategy [32, 33]. However expressive suppression was used to manage fear (17.5\%). Expressive suppression is a less effective strategy as compared to reappraisal as it does not down-regulate negative emotional experience and is positively linked to psychopathology [34]. The main reason for this is that expressive suppression is a response focused strategy, appears late in the emotion generation process; hence an individual had already subjective experience of emotion and physiological response and its only behavioural response which linger on with time and leads to the use of cognitive resources, accumulate, remained unresolved and lead to psychopathology [35].

The fourth and the last aspect of this study is that how trainees control their emotions? The Gross theory of emotion regulation describes five methods for the control of emotions. In our study, during the situation most of the trainee's AD (rumination) and CC (planning) for the control of emotions. More females (60.8\%) and Year-1 trainees (21.2\%) used these two strategies. The meta-analysis by Nolen- Hoeksema [36] also found that to deal with negative emotions, females are more likely to use rumination and need emotional support from others. Rumination is a maladaptive strategy and strong predictor for mood, anxiety disorder, depression and is associated with long working hours and work-related burnout among health care professionals [7, 37].

We found that after the situation, suppression of emotions, and crying (seeking social support) was used as a strategy in disgust and sad emotional state, particularly among females. Whereas a previous study found that the ER strategies after the situation were a physical distraction and crying outward. Monrouxe [38] found that suppression during situation and expression after the emotional experience was preferred strategies among foundation doctors in the UK. Studies done earlier [10,33] also support that suppression is positively associated with depression and negatively with the wellbeing of individual and interpersonal relations.

The ER strategies vary in the context of discrete emotions; the results differed from previous studies in which rumination was observed more in anger group than in sad emotions while comparable to fear, in which more expressive suppression was used but these two studies conducted by Zimmermann [17] in 2014 and Dixon [30] in 2015 were outside clinical settings. Results were also comparable to a study conducted by Matthew [39] in 2019 on 92 undergraduate students of Midwestern university who participated in exchange for course credit in the USA; expressive suppression was observed more in a fear state while blaming others and avoidance in anger eliciting situations.

Studies have shown that cognitive reappraisal, acceptance, problem-solving, and distraction are more successful strategies to alter emotional experience while rumination, thought suppression, avoidance, is associated with anxiety and depression [17, 30, 39]. The emotional dysregulation identified in our study among trainees not only hinders their learning, achievement, goal-oriented behaviour, and adaption to the emotion regulation process but also interferes in the process of a compassionate, caring attitude towards patients [40,41, 42].

\section{Limitations}


We have designed the instrument to cover the five major negative emotions that may need to be expanded to capture a wide range of emotions. Such as jealousy, lust, panic/grief, rage, and contempt [43].

\section{Recommendations for Further Research}

The strength of this study is that we included all years of training and all clinical disciplines for the understanding of the emotional health of trainees. This acts as a starting point for another longitudinal study on large sample size in the future on trainees across different countries to compare the intercultural variation in emotion regulation for negative emotions and response to them.

\section{Conclusions}

Trainees struggle to manage emotions and use maladaptive strategies. Sadness was the most common discrete emotion for which trainees struggle to manage all situations followed by anger, fear, disgust, and shock. More females and Year-1 trainees used these strategies to cope with sad emotions.

Trainees manage sad emotions with an outward response in the form of cry, get themselves involved in other activities, and ruminate. In anger; blame others, ruminate and think positively. While in a disgusting situation trainees avoid the situations, suppress emotions, and focus on planning. In fear; suppression of emotions, focus on the task, and taking a pill or sleep to relax were preferred strategies. In shock; positive reappraisal, acceptance, and suppression of emotion were preferred emotion regulation strategies.

Lack of cognitive coping strategies and the use of maladaptive strategies in high demanding situations identify the need for emotional development programs. Further, an introduction of mentoring programs or psychotherapies for emotionally sensitive individuals is a much-needed effort for the improvement of the mental health of trainees.

\section{Abbreviations}

AD (Attention deployment), CC (Cognitive change), ER (Emotional Regulation)

RM (Response Modulation), SS (Situational Selection), SM (Situational Modification)

\section{Declarations}

Acknowledgements: Prof Dr Shahid Iqbal, Head of Community Medicine Department Sharif Medical And Dental College, and Mr Ibrahim for data analysis.

Ethics approval and consent to participate: The study was carried out in accordance with the Declaration of Helsinki guidelines and regulations. "A written informed consent was taken from all participants". IRB approval was taken from the IRB approval committee of UOL. Ethical approval was also taken from Sharif Medical and Dental College, Nawaz Sharif Medical and Dental College Gujrat, Lady Willingdon Hospital for conducting research (Additional File).

Consent for publication: Not applicable

Availability of data and materials: All data generated or analyzed during this study is available through the first author and can be made available on request and its supplementary information in Additional files

Competing interests: UM" is an Associate Editor of BMC Medical Education. All the authors declare no competing financial and non-financial interests". This was the Master in Health Professions Education (MHPE) project of FB.UM supervised the project. GW and RAK were co-supervisors.

Funding: Source nil

\section{Authors' contributions:}

FB conceived the idea, wrote the final manuscript, help in data collection, and interpret the data.

UM: helped in study design, questionnaire development, manuscript drafting, supervised the interpretation of results, reviewed all drafts of the manuscript, and edited the final draft.

GW: Contributed to the questionnaire development process and reviewed all the drafts of the manuscript and edited the final draft.

RAK: Contributed to the questionnaire development process. Reviewed all draft, and edited the final draft.

All authors read and approved the final manuscript

Author Detail: Professor of Obstetrics and Gynaecology at Sharif Medical and Dental College, Lahore, Pakistan 
Email id: drfauziabutt@hotmail.com

\section{References}

1. Bolier M, Doulougeri K, Vries J De, Helmich E. emotion matters ' You put up a certain attitude': a 6-year qualitative study of emotional socialisation. Medical Education. 2018:1041-51.

2. Weurlander M, Lönn A, Seeberger A, Broberger E, Hult H. How do medical and nursing students experience emotional challenges during clinical placements? International Journal of Medical Education. 2018:74-82.

3. Monrouxe L, Bullock A, Rees C, Mattick K, Lall K, Lundin R, et al. Foundation doctors, transitions and emotions. Final report to GMC. 2015 ;(5):1-41.

4. Rogers ME, Creed PA, Searle J. Title: Emotional Labour, Training Stress, Burnout, and Depressive Symptoms in Junior Doctors. Journal of Vocational Education \& Training. 2014;66(2):232-48.

5. Koole S. The psychology of emotion regulation: An integrative review. Cogn Emot. 2009;23(1):4-41.

6. Gross JJ. The Extended Process Model of Emotion Regulation: Elaborations, Applications, and Future Directions. Psychological Inquiry. .2015;26:130-7.

7. Lundin RM, Bashir K, Bullock A, Kostov CE, Mattick KL, Rees CE, et al. "I'd been like freaking out the whole night": exploring emotion regulation based on junior doctors' narratives. Adv Heal Sci Educ. 2018;23(1):7-28.

8. Gross JJ. Emotion Regulation: Current Status and Future Prospects.Psychological Inquiry. $2015 ; 26: 1-26$.

9. Fiori M, Maillefer AV. Emotional Intelligence as an Ability: Theory, Challenges, and New Directions. Emotional Intelligence in Education. 2017;(6).

10. Lajoie SP, Zheng J, Li S. Examining the role of self-regulation and emotion in clinical reasoning: Implications for developing expertise. Med Teach [Internet]. 2018;0(0):1-3. Available from: https://www.tandfonline.com/doi/full/10.1080/0142159X.2018.1484084

11. Schutte NS, Manes RR, Malouff JM. Antecedent-Focused Emotion Regulation, Response Modulation and Well-Being. $2009 ; 21-31$.

12. Gross JJ. Emotion regulation: Taking stock and moving forward. Emotion. 2013;13(3):359-65.

13. Doulougeri K, Panagopoulou E, Montgomery A. (How) do medical students regulate their emotions? BMC Med Educ. 2016;16(1):1-10.

14. Gross JJ. Emotion regulation. Handb Emot [Internet]. 2008;3(31):497-512.

15. Aldao A, Nolen-Hoeksema S. One versus many: Capturing the use of multiple emotion regulation strategies in response to an emotion-eliciting stimulus. Cogn Emot. 2013;27(4):753-60.

16. Rivers SE, Brackett MA, Katulak NA, Salovey P. Regulating anger and sadness: an exploration of discrete emotions in emotion regulation. . Journal of Happiness .2007:393-427.

17. Zimmermann P, Iwanski A. Emotion regulation from early adolescence to emerging adulthood and middle adulthood: Age differences, gender differences, and emotion-specific developmental variations. Int J Behav Dev. 2014;38(2):182-94.

18. Dornan T, Pearson E, Carson P, Helmich E, Bundy C. Emotions and identity in the figured world of becoming a doctor. Med Educ. 2015;49(2):17485 .

19. Artino AR, La Rochelle JS, Dezee KJ, Gehlbach H. Developing questionnaires for educational research: AMEE Guide No. 87. Med Teach. 2014;36(6):463-74.

20. Garnefski N, Kraaij V. Cognitive emotion regulation questionnaire - development of a short 18-item version (CERQ-short). Pers Individ Dif. 2006;41(6):1045-53.

21. Rees CE, Monrouxe L V., Mcdonald LA. Narrative, emotion and action: Analysing "most memorable" professionalism dilemmas. Med Educ. 2013;47(1):80-96.

22. Helmich E, Diachun L, Lingard L, Cristancho S. workplace-based learning ' Oh my God , I can ' t handle this! ': trainees ' emotional. Med Education.2018;52:206-215.

23. Reappraisal C, Suppression E. EMOTION REGULATION QUESTIONNAIRE ( ERQ ). Journal of Personality and Social Psychology.2003; 85: 324-362.

24. Niven K, Totterdell P, Stride CB, Holman D. Emotion Regulation of Others and Self (EROS): The Development and Validation of a New Individual Difference Measure. Curr Psychol. 2011;30(1):53-73.

25. Kremer T, Mamede S, Roriz JS, Madeiro ÁJ. Emotionally Dif fi cult Experiences Faced by Medical Students During Training. Heal Prof Educ [Internet]. 2016;1-9. Available from: http://dx.doi.org/10.1016/j.hpe.2016.01.010

26. Keskitalo T. Students ' Emotions in Simulation-Based Medical Students ' Emotions in Simulation-Based Medical Education. Jl.of Interactive Learning Research. 2017; 28 (2):149-159.

27. Wall K, Kalpakci A, Hall K, Crist N, Sharp C. An evaluation of the construct of emotional sensitivity from the perspective of emotionally sensitive people. Borderline Personal Disord Emot dysregulation [Internet]. 2018 [cited 2019 Apr 21];5:14. Available from:

http://www.ncbi.nlm.nih.gov/pubmed/30155259

28. Doulougeri K, Panagopoulou E, Montgomery A. (How) do medical students regulate their emotions? BMC Med Educ [Internet]. 2016;16(1):1-10. Available from: http://dx.doi.org/10.1186/s12909-016-0832-9 
29. Tallentire VR, Smith SE, Facey AD, Rotstein L. Exploring newly qualified doctors' workplace stressors: An interview study from Australia. BMJ Open. $2017 ; 7(8)$

30. Dixon-Gordon KL, Aldao A, De Los Reyes A. Emotion regulation in context: Examining the spontaneous use of strategies across emotional intensity and type of emotion. Pers Individ Dif [Internet]. 2015;86:271-6. Available from: http://dx.doi.org/10.1016/j.paid.2015.06.011

31. Webb TL, Lindquist KA, Jones K, Avishai A. Situation selection is a particularly effective emotion regulation strategy for people who need help regulating their emotions. Cognition And Emotion. 2018;32 (2): 231-248.

32. Kobylińska D, Kusev P. Flexible emotion regulation: How situational demands and individual differences influence the effectiveness of regulatory strategies. Front Psychol. 2019;10(2):1-9.

33. Verzeletti C, Zammuner VL, Galli C, Agnoli S. Emotion regulation strategies and psychosocial well-being in adolescence. Cogent Psychol. 2016;3(1):1-15.

34. Saleem S, Ahmad Khan I, Saleem T. Anxiety and Emotional Regulation; Prof Med J. 2019;26(05): 734-741.

35. Cutuli D. Cognitive reappraisal and expressive suppression strategies role in the emotion regulation: An overview on their modulatory effects and neural correlates. Front Syst Neurosci. 2014;8(9):1-6.

36. Nolen-Hoeksema S. Emotion Regulation and Psychopathology: The Role of Gender. Annu Rev Clin Psychol. 2012;8(1):161-87.

37. Vandevala T, Pavey L, Chelidoni O, Chang NF, Creagh-Brown B, Cox A. Psychological rumination and recovery from work in intensive care professionals: Associations with stress, burnout, depression and health. J Intensive Care. 2017;5(1):1-8.

38. Monrouxe L, Bullock A, Cole J, Gormley G. How Prepared are UK Medical Graduates for Practice? Final Rep from a Program Res Comm by Gen Med Council [Internet]. 2014;(6):1-273.

39. Matthew W. Southwarda, Jane E. Heiyb, Jennifer S. Cheavens. Emotions as context: Do the naturalistic effects of emotion regulation strategies depend on the regulated emotion? J Soc Clin Psychol.2019 (6); 38 (6) :451-474.

40. Arslan R, Counseling P, Counseling P. The Relationship between Interpersonal Emotion Regulation and Interpersonal Competence Controlled for Emotion Dysregulation. 2019;8(1):69-76.

41. Cherry MG, Fletcher I, O’Sullivan H, Dornan T. Emotional intelligence in medical education: A critical review. Med Educ. 2014;48(5):468-78.

42. Pekrun R, Stephens EJ. Achievement Emotions: A Control-Value Approach. 2010;4:238-55.

43. Kowalska M, Wrobel M. Encyclopedia of Personality and Individual Differences. Encycl Personal Individ Differ. 2017; 7. DOI: 10.1007/978-3-31928099-8_495-1

\section{Tables}

Table 1: Demographics Detail of study participants

\begin{tabular}{|c|c|c|c|c|c|c|c|c|c|c|}
\hline Training & Clinical Speci & & & & & & & & & \\
\hline & $\begin{array}{l}\text { Obstetrics \& } \\
\text { Gynaecology }\end{array}$ & Medicine & Surgery & Anaesthesia & Paediatrics & Orthopaedic & Cardiology & Radiology & Neurosurgery & Total \\
\hline Year-1 & 45 & 11 & 35 & 4 & 8 & 1 & 1 & 4 & 7 & 116 \\
\hline Year-2 & 26 & 6 & 12 & 9 & 7 & 2 & 3 & 7 & 5 & 77 \\
\hline Year-3 & 27 & 3 & 10 & 1 & 4 & 1 & 4 & 0 & 1 & 52 \\
\hline \multirow[t]{2}{*}{ Year-4 } & 35 & 11 & 4 & 4 & 2 & 0 & 7 & 0 & 0 & 63 \\
\hline & 133 & 31 & 61 & 18 & 21 & 4 & 15 & 11 & 13 & 308 \\
\hline
\end{tabular}

Table 2: Frequency and pattern of emotional responses in emotion stimulating situations 


\begin{tabular}{|c|c|c|c|c|c|c|c|c|c|}
\hline \multirow[t]{2}{*}{ Situations } & \multirow[t]{2}{*}{ \%age } & \multicolumn{8}{|c|}{ *Emotional Responses } \\
\hline & & a & $\mathrm{b}$ & c & $d$ & e & $f$ & g & $\mathrm{h}$ \\
\hline \multicolumn{10}{|c|}{ The humiliation of junior colleagues by senior colleagues in front of patients } \\
\hline & 81 & 44 & 11 & 11 & 27 & 4.8 & 1 & 16 & 3 \\
\hline \multicolumn{10}{|c|}{ Incident of the uncivil and rude behavior of doctors towards patients } \\
\hline & 63 & 29.6 & 21 & 10.2 & 8.7 & 10.2 & 3.6 & 21 & 3 \\
\hline \multicolumn{10}{|c|}{ Wrong dispensing of medicines to patients by staff } \\
\hline & 50.3 & 12.3 & 8.4 & 36.8 & 3.2 & 8.4 & 8.4 & 26.5 & 6.5 \\
\hline Inadequate health care facilities & 78.8 & 16 & 10 & 22 & 15 & 3 & 8.6 & 36.6 & 4.5 \\
\hline \multicolumn{10}{|c|}{ Rude behavior of patients or their attendants towards staff } \\
\hline & 94 & 60 & 11.8 & 32.2 & 13. & 5.9 & 3.1 & 17.6 & 6 \\
\hline \multicolumn{10}{|c|}{ When I lose a patient, in spite of my best efforts to save his life } \\
\hline & 56 & 33.9 & 14.9 & 9.2 & 19 & 4 & 2.9 & 19.5 & 6.9 \\
\hline \multicolumn{10}{|c|}{$\begin{array}{l}\text { I am unable to treat the patient satisfactorily, due to my busy schedule and } \\
\text { shortage of time }\end{array}$} \\
\hline & 66 & 22.8 & 20.8 & 17.3 & 10.4 & 5 & 5 & 17.3 & 8.9 \\
\hline \multicolumn{10}{|c|}{ Breaking the bad news to the patient or his/her relatives } \\
\hline & 80 & 21.9 & 13.8 & 6.5 & 9 & 4.9 & 1.6 & 29.1 & 22 \\
\hline \multicolumn{10}{|c|}{ Prolonged working hours in a hospital } \\
\hline & 95 & 16 & 16 & 36.6 & 24. & 5.5 & 4.5 & 8.2 & 4.8 \\
\hline \multicolumn{10}{|c|}{ Miscommunication between nursing staff and doctors } \\
\hline & 73 & 18.1 & 15.5 & 23.9 & 8 & 7.5 & 4.9 & 26.5 & 5.8 \\
\hline
\end{tabular}

*Values are presented as percentages, \%, *Emotional response: a. I remain quiet, b: I become confused and uncertain, c: I become agitated and aggressive, $\mathbf{d}$ :I lose interest in work, $\mathbf{e}$ : I have nonparticipating behavior, f: I blame others, g: discuss the situation with others, $\mathbf{h}$ : any other

Table 3: Frequency and pattern of emotional regulation strategies in negative emotions 


\begin{tabular}{|c|c|c|c|c|c|c|}
\hline Items & Strategies & Disgust & Sad & Angry & Fear & Shock \\
\hline & Before & & & & & \\
\hline 1. & Situation Selection(SS) & 29.2 & 33.4 & 28.9 & 14.3 & 4.2 \\
\hline 2. & Situation Modification (SM) & 17.2 & 49.4 & 26.6 & 13 & 4.2 \\
\hline 3. & Reappraisal (CC) & 18.5 & 38.3 & 30.8 & 14.3 & 6.8 \\
\hline 4. & Expressive suppression (AD) & 17.5 & 38.3 & 28.6 & 17.5 & 6.2 \\
\hline \multicolumn{7}{|l|}{ During } \\
\hline 5. & Planning (CC) & 24 & 39 & 24 & 16.6 & 8.8 \\
\hline 6. & Reappraisal (CC) & 14 & 39.5 & 23.4 & 21.1 & 8.8 \\
\hline 7. & Acceptance (CC) & 21.8 & 34.1 & 24 & 15.9 & 12.7 \\
\hline 8. & Humor (AD) & 23.7 & 33.1 & 31.5 & 11.4 & 6.8 \\
\hline 9. & Catastrophizing (CC) & 23.4 & 36.4 & 24.4 & 16.6 & 6.2 \\
\hline 10. & Blame others (CC) & 19.8 & 26 & 40.3 & 12.3 & 8.1 \\
\hline 11. & Rumination (AD) & 18.5 & 30.2 & 32.8 & 18.2 & 4.2 \\
\hline 12. & Distraction (AD) & 15.9 & 37.0 & 26.9 & 23.1 & 6.8 \\
\hline \multirow[t]{2}{*}{13.} & Expression of emotion (RM) & 15.6 & 41.6 & 29.5 & 22.7 & 5.5 \\
\hline & After & & & & & \\
\hline 14. & Rumination & 17.2 & 32 & 28.9 & 22.7 & 7.5 \\
\hline 15. & Suppression of emotions & 28.9 & 39.6 & 23.7 & 16.6 & 8.4 \\
\hline 16. & Outward (Cry) & 17.9 & 50.6 & 28.9 & 11.7 & 7.1 \\
\hline 17. & Take a sleep or some medicine as a pill to relax & 19.5 & 40.6 & 25.6 & 21.1 & 5.8 \\
\hline \multirow[t]{2}{*}{18.} & Distraction from situation (Walk, exercise, shopping, watch TV or read) & & & & & \\
\hline & & 17.5 & 45.8 & 33.1 & 16.9 & 6.5 \\
\hline
\end{tabular}

*Values presented as percentages

*SS: situation selection, SM: Situation modification, AD: Attention Deployment, CC: Cognitive Change, RM: Response Modulation

Table 4: Comparison of strategies used in the sadness among gender group

\begin{tabular}{|c|c|c|c|c|c|}
\hline & \multirow[t]{2}{*}{ Strategies } & \multicolumn{3}{|c|}{ Gender } & \multirow[t]{2}{*}{ P value } \\
\hline & & Male & Female & Total & \\
\hline & Situation selection (SS) & 11.4 & 22.1 & $33.4 \%$ & 0.891 \\
\hline \multirow[t]{2}{*}{ Before } & Situation modification (SM) & 14 & 35.4 & $49.5 \%$ & 0.08 \\
\hline & Planning (CC) & 14.3 & 24.7 & $39 \%$ & 0.29 \\
\hline \multirow[t]{2}{*}{ During } & Rumination (AD) & 12.0 & 29.5 & $41.5 \%$ & 0.18 \\
\hline & Suppression of emotion (RM) & 13.6 & 26 & $39.6 \%$ & 0.69 \\
\hline After & Outward/crying (RM) & 14.3 & 31.5 & $17.8 \%$ & 0.15 \\
\hline
\end{tabular}

*Values presented as percentages among Gender Group 
Table 5: Mean difference in the use of emotion regulation strategies among five negative emotions (Repeated Measure ANOVA)

\begin{tabular}{|c|c|c|c|c|}
\hline Emotions & Strategies & Mean \pm SD* & F-Ratio* & P-Value* \\
\hline \multirow[t]{3}{*}{ Disgust } & Disgust while encountering the situation & $0.83 \pm 0.846$ & \multirow[t]{3}{*}{544.932} & \multirow[t]{3}{*}{0.000} \\
\hline & Disgust during the situation & $1.94 \pm 1.664$ & & \\
\hline & Disgust after the situation & $0.84 \pm 1.005$ & & \\
\hline \multirow[t]{3}{*}{ Sadness } & Sadness while encountering the situation & $1.63 \pm 1.075$ & \multirow[t]{3}{*}{1823.863} & \multirow[t]{3}{*}{0.000} \\
\hline & Sadness during the situation & $3.49 \pm 1.799$ & & \\
\hline & Sadness after the situation & $1.52 \pm 1.064$ & & \\
\hline \multirow[t]{3}{*}{ Angry } & Angry while encountering situation & $1.16 \pm 0.883$ & \multirow[t]{3}{*}{1056.394} & \multirow[t]{3}{*}{0.000} \\
\hline & Angry during the situation & $2.86 \pm 1.928$ & & \\
\hline & Angry after the situation & $1.12 \pm 1.054$ & & \\
\hline \multirow[t]{3}{*}{ Fear } & Fear while encountering situation & $0.59 \pm 0.798$ & \multirow[t]{3}{*}{993.434} & \multirow[t]{3}{*}{0.000} \\
\hline & Fear during the situation & $2.86 \pm 1.928$ & & \\
\hline & Fear after the situation & $1.05 \pm 0.992$ & & \\
\hline \multirow[t]{3}{*}{ Shock } & Shock while encountering situation & $0.22 \pm 0.511$ & \multirow[t]{3}{*}{136.122} & \multirow[t]{3}{*}{0.000} \\
\hline & Shock during the situation & $0.76 \pm 1.099$ & & \\
\hline & Shock after the situation & $0.31 \pm 0.916$ & & \\
\hline
\end{tabular}

* Significant $\mathrm{p}$ value $<0.05, \mathrm{SD}^{*}=$ standard Deviation; F-ratio* is a statistical value to represent Repeated Measure ANOVA. The higher value means rejection of the null hypothesis

\section{Figures}




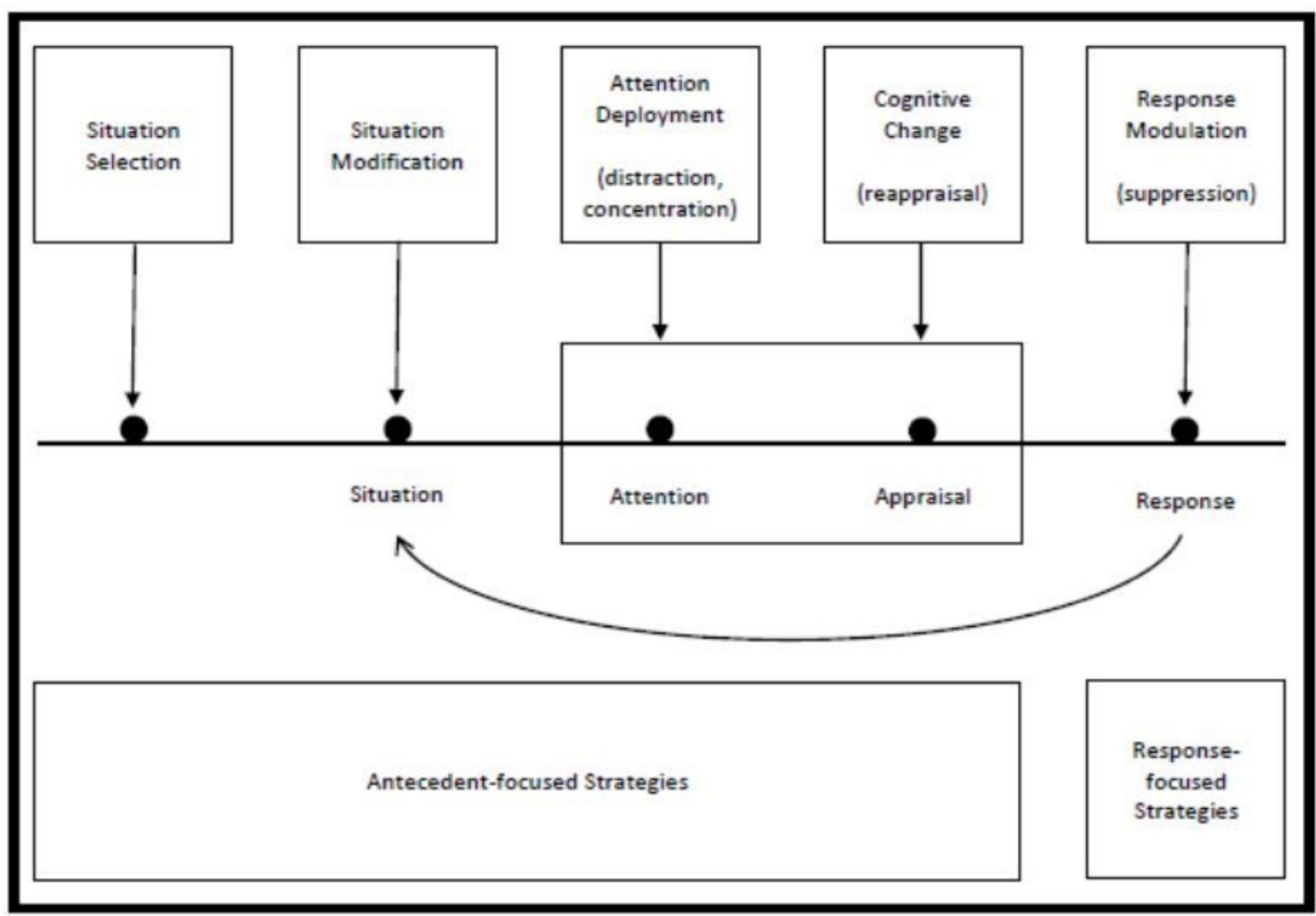

Figure 1

Gross Process Model of Emotion Regulation

\section{Situational Model of Emotion Regulation}

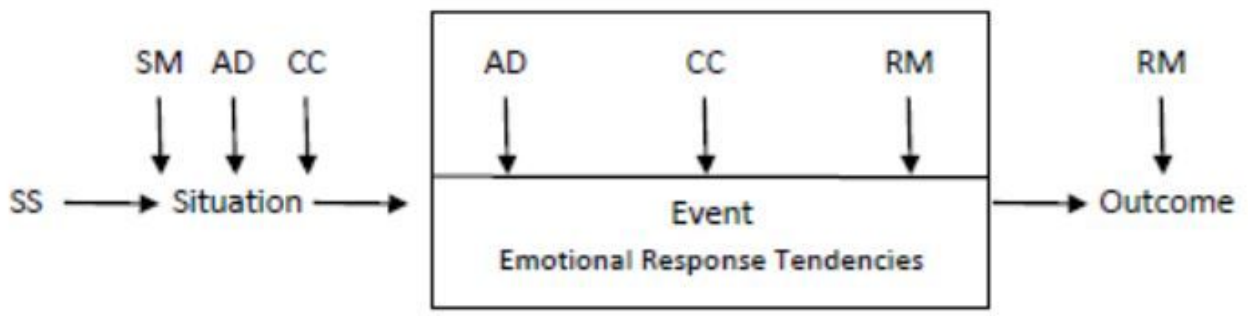

Prior

During

After

Strategies

Situation Selection (SS):

Situation Modification (SM):

Attention Deployment (AD):

Cognitive Change (CC):

Response Modulation (RM):
Subcategories

None

None

Distraction from Emotion, Distraction from situation and Rumination Reappraisal, Cognitive Reframing, Humour, Downwards Social Comparison, Using Clinical Skills, Using Information, Esteem Support and Emotional Support

Outwards, Inwards and Physical 
Figure 2

Situational Model of Emotion Regulation

\section{Supplementary Files}

This is a list of supplementary files associated with this preprint. Click to download.

- AdditionalFile3.zip

- Additionalfile1.zip

- Additionalfile2.zip 